Research Article

\title{
Cardiovascular Magnetic Resonance Imaging Evidence of Edema in Chronic Chagasic Cardiomyopathy
}

\author{
Andrés Diaz $\mathbb{D}^{1},{ }^{1,2,3}$ Juan José Diaztagle, ${ }^{1,2,4}$ Alejandro Olaya, ${ }^{1,2}$ Guillermo Mora, ${ }^{4,5}$ \\ Ignacio López-Lima, ${ }^{6}$ Carolina Ayala, ${ }^{2,3}$ Gina P. P. Infante, ${ }^{2,7}$ Néstor Galizio, ${ }^{8}$ \\ Frida T. Manrique, ${ }^{9}$ Julian F. Forero, ${ }^{9}$ Hector M. Medina, ${ }^{9}$ and Josep Brugada ${ }^{3,10}$ \\ ${ }^{1}$ Hospital San José, Bogotá, Colombia \\ ${ }^{2}$ Fundación Universitaria de Ciencias de la Salud, Bogotá, Colombia \\ ${ }^{3}$ Escola de Doctorat, Universitat de Barcelona, Barcelona, Spain \\ ${ }^{4}$ Facultad de Medicina, Universidad Nacional de Colombia, Bogotá, Colombia \\ ${ }^{5}$ Fundación Santa Fe de Bogotá, Bogotá, Colombia \\ ${ }^{6}$ Hospital Dr. Guillermo Rawson, San Juan, Argentina \\ ${ }^{7}$ Statistical Analysis and Research Consulting, Bogotá, Colombia \\ ${ }^{8}$ Hospital Universitario Fundación Favaloro, Buenos Aires, Argentina \\ ${ }^{9}$ Departamento de Imagen Diagnóstica, Fundación Cardioinfantil, Bogotá, Colombia \\ ${ }^{10}$ Hospital Clínic de Barcelona, Barcelona, Spain \\ Correspondence should be addressed to Andrés Diaz; andresdiaz1992@live.com
}

Received 20 December 2018; Revised 4 May 2019; Accepted 15 June 2019; Published 5 September 2019

Academic Editor: Syed Wamique Yusuf

Copyright (c) 2019 Andrés Diaz et al. This is an open access article distributed under the Creative Commons Attribution License, which permits unrestricted use, distribution, and reproduction in any medium, provided the original work is properly cited.

\footnotetext{
The persistence of inflammatory processes in the myocardium in varying degrees of chronic Chagas heart disease has been poorly investigated. We hypothesized that edema could occur in patients with chronic chagasic cardiomyopathy and corresponds to the persistence of inflammatory processes in the myocardium. Eighty-two Chagas disease (CD) seropositive patients $(64.6 \%$ females; age $=58.9 \pm 9.9)$ without ischemic heart disease or conditions that cause myocardial fibrosis and dilation were considered. Late gadolinium enhancement (LGE) and T2-weighted magnetic resonance imaging of edema were obtained and represented using a 17-segment model. Patients were divided into three clinical groups according to the left ventricular (LV) ejection fraction (EF) as G1 (EF $>60 \% ; n=37)$, G2 $(35 \%>\mathrm{EF}<60 \% ; n=33)$, and G3 (EF $<35 \% ; n=12)$. Comparisons were performed by the Fisher or ANOVA tests. Bonferroni post hoc, Spearman correlation, and multiple correspondence analyses were also performed. Edema was observed in 8 (9.8\%) patients; 2 (5.4\%) of G1, 4 (12.1\%) of G2, and $2(16.7 \%)$ of G3. It was observed at the basal inferolateral segment in $7(87.5 \%)$ cases. LGE was observed in $48(58.5 \%)$ patients; $16(43.2 \%)$ of G1, $21(63.6 \%)$ of G2, and $11(91.7 \%)$ of G3 $(p<0.05)$. It was observed in the basal inferior/ inferolateral/anterolateral segments in $35(72.9 \%)$ patients and in the apical anterior/inferior/lateral and apex segments in 21 $(43.7 \%)$, with midwall $(85.4 \% ; n=41)$, subendocardial $(56.3 \% ; n=27)$, subepicardial $(54.2 \% ; n=26)$, transmural $(31.2 \%$; $n=15)$, and RV $(1.2 \% ; n=1)$ distribution. Subendocardial lesions were observed only in patients with LVEF $<35 \%$. There was no involvement of the mid-inferolateral/anterolateral segments with an LVEF $>35 \%(p<0.05)$. Deteriorations of the LV and RV systolic functions were positively correlated $\left(r_{s}=0.69 ; p<0.05\right)$ without evidence of LGE in the RV. Edema can be found in patients with chagasic cardiomyopathy in the chronic stage. In later stages of cardiac dilation with low LVEF, the LGE pattern involves subendocardium and mid locations. Deteriorations of RV and LV are positively correlated without evidence of fibrosis in the RV.
} 


\section{Introduction}

Chagasic heart disease, caused by Trypanosoma cruzi infection, is a pathology of crucial interest in public health. The vectors, bug members of the subfamily Triatominae, are hematophagous insects distributed mainly from the southern United States to South America [1]. It is estimated that 8 to 10 million people are infected in the world [2]. In the Americas, the incidence is approximately 41,200 new cases per year and it is estimated that $108,595,000$ people are at risk [3]. Additionally, in this continent, almost two million women in reproductive age are infected, of which 4 to $8 \%$ would transmit the infection to the fetus [4]. In Colombia, between 700,000 and 1,200,000 inhabitants are infected and 8,000,000 individuals are at risk of acquiring the infection [5].

After infection with T. cruzi, the asymptomatic phase can last for decades until unknown triggers initiate cardiac involvement in $>90 \%$ of the cases [6], which is mainly characterized by chronic myocarditis that involves interstitial and diffuse fibrosis [7]. This is a crucial clinical aspect of Chagas disease because of its poor prognosis [810]. In fact, in a Brazilian hospital-based cohort of 1220 outpatients with heart failure of different etiologies, Chagas heart disease was the main prognostic factor for mortality [9]. Typically, death occurs in men between 33 and 72 years, affecting mainly vulnerable populations [11].

Recently, cardiac magnetic resonance (CMR) has been considered a sensitive technique to detect myocardial damage in Chagas heart disease $[6,12-14]$; it is suitable to detect segmental wall motion abnormalities, particularly myocardial necrosis or fibrosis using the late gadolinium enhancement (LGE) technique [13-18] and heralds an adverse prognosis in nonischemic cardiomyopathy [19]. Grothues et al. reported CMR as the best method to assess ventricular function with an excellent interstudy reproducibility superior to two-dimensional echocardiography in normal, dilated, and hypertrophic hearts. In addition, CMR has demonstrated to detect myocardial edema using T2-weighted myocardial early gadolinium enhancement image sequences [20-22]. Nonetheless, this method has been scarcely used in the study of Chagas heart disease, and the findings that can guide the treatment and prognosis of those patients are unknown, especially in countries of greater risk and vulnerability. In this way, recognition of the CMR pattern of Chagas heart disease would be useful to detect myocardial involvement of patients in different clinical phases of this disease. Consequently, decisions regarding therapy, including heart transplantation, can be supported by CMR findings and in the knowledge of the long-term prognosis of affected patients $[9,14,18]$. Thus, the aim of this study is to characterize CMR findings in Chagas-seropositive patients and to confirm the hypothesis that edema could occur in patients with chronic chagasic cardiomyopathy and corresponds to the persistence of the inflammatory process in the myocardium.

\section{Materials and Methods}

This study was performed with 82 patients in different clinical phases of Chagas heart disease. Patients were divided into groups according to the left ventricular (LV) ejection fraction $(\mathrm{EF})$ as $\mathrm{G} 1(\mathrm{EF}>60 \% ; n=37), \mathrm{G} 2(35 \%<\mathrm{EF}>60 \%$; $n=33)$, and $\mathrm{G} 3(\mathrm{EF}<35 \% ; n=12)$. Sociodemographic data, clinical history, and comorbidities were obtained from patients' medical records. The inclusion criteria were patients over 18 years old, positive for Chagas disease according to the CDC criteria, epidemiological background, and two positive laboratory tests (immunoenzymatic assay testsELISA, and indirect immunofluorescence-IFI). Each patient signed a consent form to be part of the study.

The exclusion criteria considered refusal of the patient or their relatives to participate in the study diagnosis of coronary disease; dilated cardiomyopathy of ischemic origin and/or significant valvular disease; contraindications to magnetic resonance; presence of tattoos, metallic pigments, nonremovable metal prostheses, metallic sutures and/or heart devices not compatible with magnetic resonance; pregnancy; fever; severe claustrophobia; severe psychiatric disorders; creatinine $<30 \mathrm{~mL} /$ minute in a 24-hour depuration test; and contraindication to gadolinium as a contrast medium.

Patients were recruited from the cardiology, electrophysiology, emergency, and hospitalization services of seven cardiovascular reference hospitals of the city of Bogotá DC, Colombia.

2.1. Magnetic Resonance Imaging Methods. CMR was performed in all selected patients using a Philips Ingenia $1.5 \mathrm{~T}$ scanner. The exploration protocol comprised an initial morphological evaluation considering bright and blackblood gradient-echo sequences in the axial and coronal planes. The functional evaluation considered maps of $\mathrm{T} 1$ and T2 sequences of cine resonance with the technique of steadystate free precession (SSFP). Additionally, a quantitative functional evaluation was carried out. Structural measures (diastolic and systolic diameter of the left ventricle, diastolic thickness of the walls, anterior systolic left atrial diameter, volume of the left atrium in two dimensions, mean lateral diameter of the right ventricle, and presence of pericardial effusion) and functional measures (ejection fraction of the left ventricle, estimation of pulmonary arterial pressure, and presence and degrees of mitral and tricuspid regurgitation) were obtained from each patient. Tissue characterization evaluated the presence of myocardial edema by means of T2 sequences with fat suppression and the presence of LGE with T1 IR acquisitions in 2D and 3D. Additionally, images of LGE were obtained specifying the location and degree of transmurality. The intravenous contrast material used was Gadobutrol ( $0.1 \mathrm{mmol} / \mathrm{kg})$, a gadolinium-based MRI contrast agent.

The interpretation of the resonances was carried out by specialists in radiology and diagnostic images of the participating institutions. A second reading of the study was made by an expert in advanced cardiac imaging with experience in cardiovascular magnetic resonance analysis; the specialists were blinded with respect to the previous analysis, in order to estimate the reproducibility of the imaging variables obtained in the study. 
TABLE 1: Clinical characteristics of Chagas heart disease patients classified by groups.

\begin{tabular}{|c|c|c|c|c|c|}
\hline & Total $n=82$ & $\begin{array}{c}\text { Group } 1 \\
\mathrm{FE}>60 \% n=37\end{array}$ & $\begin{array}{c}\text { Group 2 } \\
60 \%<\mathrm{FE}>35 \% n=33\end{array}$ & $\begin{array}{c}\text { Group } 3 \\
\mathrm{FE}<35 \% n=12\end{array}$ & $p$ value \\
\hline Age (years) & 58.9 (SD 9.9) & 57.6 (SD 11.0) & 58.8 (SD 9.1) & $63.0(\mathrm{SD} 7.7)$ & 0.13 \\
\hline BMI & $26.2(\mathrm{SD} 4.3)$ & $26.7(\mathrm{SD} 3.9)$ & $26.0(\mathrm{SD} 4.3)$ & $25.6(\mathrm{SD} 5.7)$ & 0.38 \\
\hline Socioeconomic & $2.0(\mathrm{SD} 1.0)$ & $2.25(\mathrm{SD} 1.0)$ & 1.42 (SD 0.99) & $1.4(\mathrm{SD} 0.7)$ & $0.02 \bar{\Sigma}$ \\
\hline Female (\%) & $53(64.6)$ & $30(81.0)$ & $18(54.5)$ & $5(41.7)$ & $0.013 \bar{\Sigma}$ \\
\hline Blood pressure (\%) & $39(47.6)$ & $18(50.0)$ & $12(40.0)$ & $9(75.0)$ & 0.12 \\
\hline Type 2 diabetes (\%) & $7(8.9)$ & $4(11.1)$ & $2(6.7)$ & $1(8.3)$ & 0.82 \\
\hline DLP (\%) & $12(15.4)$ & $8(22.2)$ & $2(6.7)$ & $2(16.7)$ & 0.22 \\
\hline Smoking (\%) & $3(3.8)$ & $0(0)$ & $2(6.7)$ & $1(8.33)$ & 0.25 \\
\hline NYHA & $1.5(\mathrm{SD} 0.5)$ & $1.4(\mathrm{SD} 0.5)$ & $1.4(\mathrm{SD} 0.6)$ & $1.7(\mathrm{SD} 0.4)$ & 0.19 \\
\hline \multicolumn{6}{|l|}{ CMR } \\
\hline LGE (\%) & $48(58.5)$ & $16(43.2)$ & $21(63.6)$ & $11(91.7)$ & $0.01 * \bar{\Sigma}$ \\
\hline FEVD & $54.2(\mathrm{SD} 9.8)$ & $58.6(\mathrm{SD} 5.5)$ & $55.0(\mathrm{SD} 6.8)$ & $38.2(\mathrm{SD} 11.6)$ & $0.01 * \bar{r}$ \\
\hline LV telediastolic volume & $153.2(\mathrm{SD} 60.5)$ & $123.0(\mathrm{SD} 32.1)$ & $149.0(\mathrm{SD} 39.7)$ & $256(\mathrm{SD} 67.2)$ & $0.01 * \bar{\varnothing} \odot$ \\
\hline LV telediastolic volume index & $87.1(\mathrm{SD} 34.7)$ & $70.9($ SD 16.9) & $82.5(\mathrm{SD} 24.7)$ & $150.6(\mathrm{SD} 29.8)$ & $0.01 \nLeftarrow \bar{\Sigma}$ \\
\hline LV telesystolic volume & $78.5(\mathrm{SD} 60.1)$ & $43.5(\mathrm{SD} 14.1)$ & $74.5(\mathrm{SD} 33.0)$ & $197.0(\mathrm{SD} 57.0)$ & $0.01 * \bar{\varnothing} \bigcirc$ \\
\hline LV telesystolic volume index & $44.2(\mathrm{SD} 35.8)$ & $24.3(\mathrm{SD} 7.6)$ & $41.0(\mathrm{SD} 20.1)$ & $114.0(\mathrm{SD} 26.5)$ & $0.01 * \bar{\Sigma} \bigcirc$ \\
\hline LV mass & $105.4(\mathrm{SD} 40.6)$ & 87.7 (SD 19.7) & 98.5 (SD 25.5) & $163.0(\mathrm{SD} 54.7)$ & $0.01 * \bar{\Sigma}$ \\
\hline LV mass index & $57.9(\mathrm{SD} 21.3)$ & $49.2(\mathrm{SD} 13.4)$ & $53.0(\mathrm{SD} 15.3)$ & 89.7 (SD 20.0) & $0.01 * \bar{\Sigma}$ \\
\hline VD telediastolic volume & $128.1(\mathrm{SD} 42.4)$ & $122.0(\mathrm{SD} 35.3)$ & $132.0(\mathrm{SD} 41.9)$ & $136.0(\mathrm{SD} 62.1)$ & 0.48 \\
\hline VD telediastolic volume index & $72.1(\mathrm{SD} 21.3)$ & $69.5(\mathrm{SD} 18.1)$ & $73.1(\mathrm{SD} 24.1)$ & $77.4(\mathrm{SD} 23.0)$ & 0.51 \\
\hline VD telesystolic volume & $58.9(\mathrm{SD} 29.2)$ & $49.8(\mathrm{SD} 16.1)$ & $60.2(\mathrm{SD} 27.0)$ & $83.9(\mathrm{SD} 48.4)$ & $0.01 \% \bar{\Sigma}$ \\
\hline VD telesystolic volume index & $33.9(\mathrm{SD} 15.1)$ & $28.5(\mathrm{SD} 8.3)$ & $34.8(\mathrm{SD} 16.0)$ & $48.2(\mathrm{SD} 19.5)$ & $0.01 * \bar{\Sigma}$ \\
\hline \multicolumn{6}{|l|}{$L G E$} \\
\hline Transmural (\%) & $15(31.2)$ & $3(18.7)$ & $8(38.1)$ & $4(41.6)$ & 0.41 \\
\hline Subendocardic (\%) & $27(56.2)$ & $7(43.7)$ & $10(47.6)$ & $10(90.9)$ & $0.03 \%$ \\
\hline Subepicardic (\%) & $26(54.2)$ & $7(43.7)$ & $14(66.7)$ & $5(45.4)$ & 0.31 \\
\hline Midwall (\%) & $41(85.4)$ & $12(75.0)$ & $20(95.2)$ & $9(81.8)$ & 0.21 \\
\hline Basal segments* (\%) & $35(72.9)$ & $10(62.5)$ & $18(85.7)$ & $7(63.6)$ & 0.21 \\
\hline Apical segments* (\%) & $21(43.7)$ & $6(37.5)$ & $7(33.3)$ & $8(72.7)$ & 0.08 \\
\hline Midcavity segments* (\%) & $18(37.5)$ & $4(25.0)$ & $7(33.3)$ & $7(63.7)$ & 0.11 \\
\hline \multicolumn{6}{|l|}{ Laboratory } \\
\hline Creatinine & $0.9(\mathrm{SD} 0.2)$ & $0.84(\mathrm{SD} 0.2)$ & $0.89(\mathrm{SD} 0.2)$ & $1.1(\mathrm{SD} 0.3)$ & 0.00 \\
\hline BUN & $17.6(\mathrm{SD} 7.9)$ & $16.2(\mathrm{SD} 5.6)$ & $18.5(\mathrm{SD} 8.3)$ & $19.4(\mathrm{SD} 11.6)$ & 0.34 \\
\hline
\end{tabular}

Continuous variables are expressed as mean (SD, standard deviation). Categorical variables are expressed as the number of patients (\%). BMI: body mass index; NYHA FC: New York Heart Association functional class. Post hoc comparisons between groups were not statistically significant otherwise indicated $\odot$ : significant difference between G2 and G1; 조: significant difference between G3 and G1; significant difference between G3 and G2.

*Obtained from http://www.pmod.com/files/download/v34/doc/pcardp/3615.htm.

2.2. Statistical Analysis. Comparisons of normally distributed continuous variables between groups were performed by the one-way analysis of variance (ANOVA) with the Bonferroni post hoc test for multiple comparisons. The nonparametric test for discrete variables and nonnormal continuous variables was the Kruskal-Wallis test by ranks. Normality was determined by the Shapiro-Wilk test. The Fisher exact test was used for proportion comparisons between the groups. A confidence level of $95 \%$ was used to considered test results statistically significant.

Multiple correspondence analysis (MCA), a multivariate data analysis, was employed to construct relationships among categorical variables associated with the presence and location of LGE in the different LVEF groups. Chi-squared tests were performed to verify the association between categorical variables. All statistical analyses were performed using the $\mathrm{R}$ language [23].

\section{Results and Discussion}

Table 1 summarizes clinical characteristics for each group according to the considered variables. The median age was 58.9 years (ranging from 33 to 80 ), 64.6\% were women, and the mean body mass index was 26.2 (SD 4.35). Some of these patients suffered from high blood pressure (47.6\%), diabetes mellitus (8.9\%), and dyslipidemia (15.4\%) or were smokers (3.8\%). Those patients were classified in the NYHA functional class I $(54.9 \%: n=45)$, class II $(43.9 \% ; n=36)$, and class III $(1.2 \% ; n=1)$.

LGE was observed in 48 (58.5\%) patients; $16(43.2 \%)$ of G1, $21(63.6 \%)$ of G2, and $11(91.7 \%)$ of G3 $(p<0.05)$. It was observed in the basal inferior/inferolateral/anterolateral segments in $35(72.9 \%)$ patients and in the apical anterior/ inferior/lateral and apex segments in $21(43.7 \%)$ patients, with midwall $(85.4 \% ; n=41)$, subendocardial $(56.2 \%$; $n=27)$, subepicardial $(54.2 \% ; n=26)$, transmural $(31.2 \%$; 


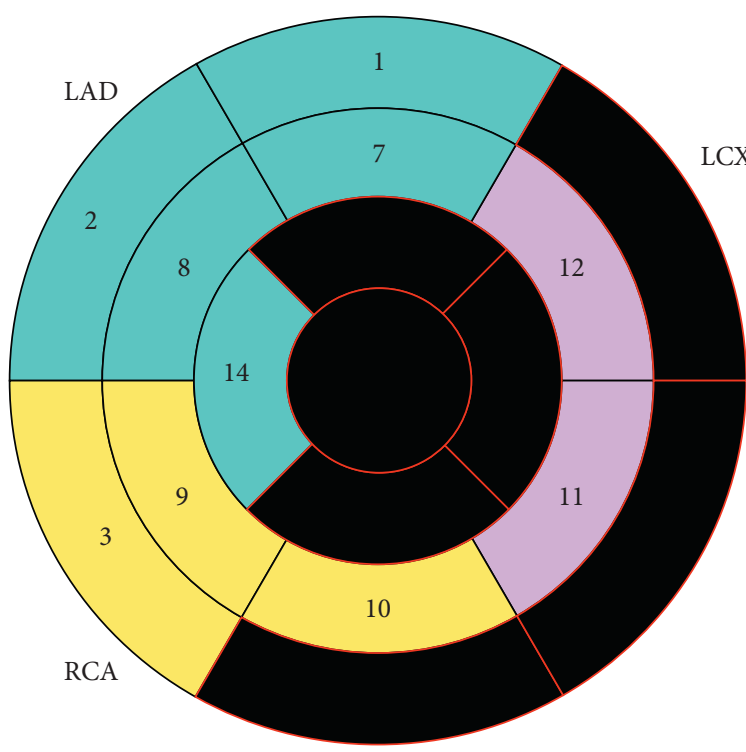

(a)

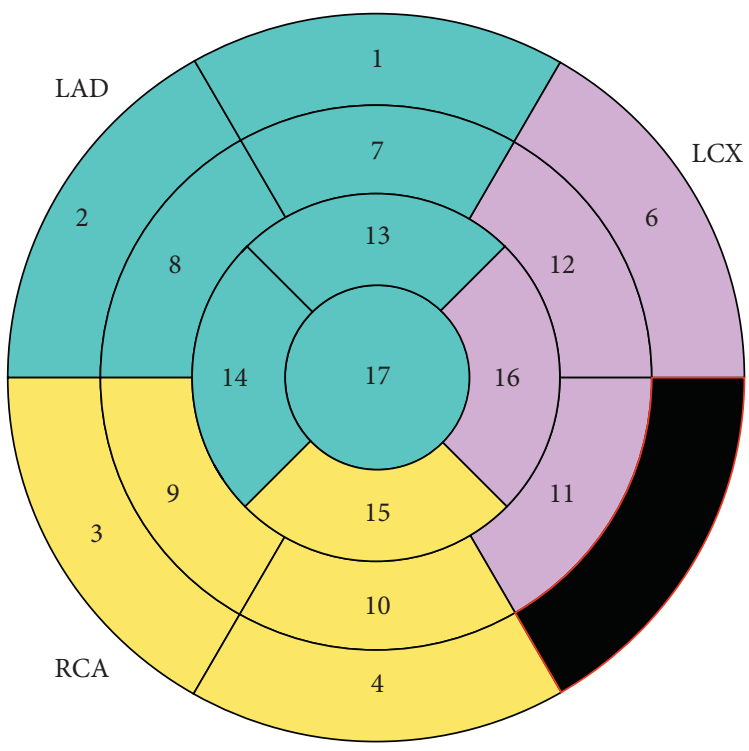

(b)

FIGURE 1: Results of the (a) LGE and (b) edema distribution in a 17-segment heart model. LAD: left anterior descending; RCA: right coronary artery; LCX: left circumflex. Modified from http://www.pmod.com/files/download/v34/doc/pcardp/3615.htm.

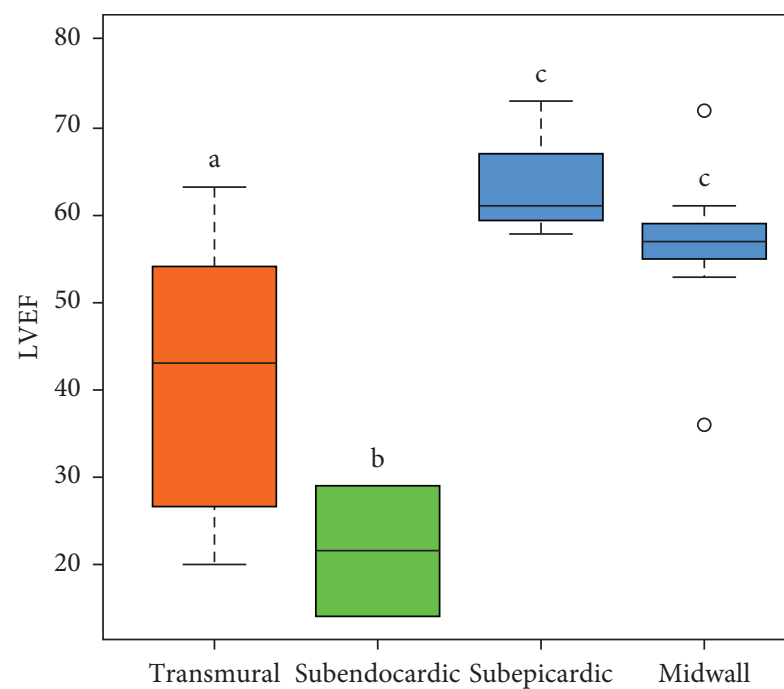

(a)

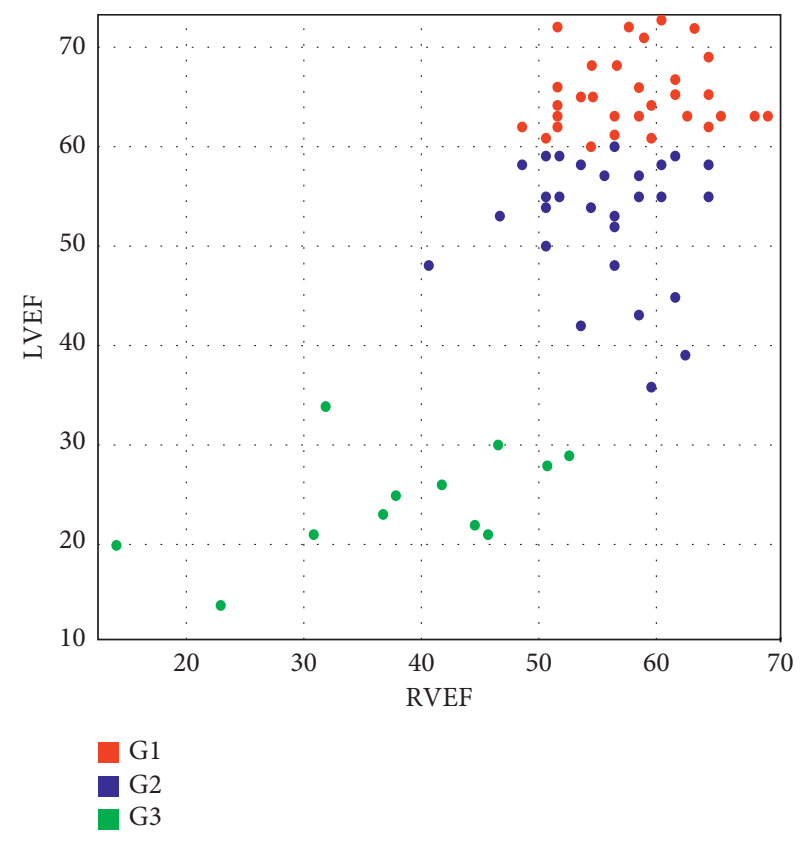

(b)

FIgURE 2: (a) LVEF of different LGE distributions and (b) scatterplot of LVEF and RVEF between groups $\left(r_{s}=0.69\right)$.

$n=15)$, and RV $(1.2 \% ; n=1)$ distribution. The distribution of LGE in a 17-segment model (AHA) is shown in Figure 1(a). Subendocardial lesions were more frequently observed in patients with LVEF $<35 \% \quad(p<0.05)$ (Figure 2(a)). Those patients also presented a greater involvement of the apical and mesial segments $(p<0.05)$. There was no involvement of the midwall and subepicardial segments with an LVEF $>35 \%(p<0.05)$ (Figure $2(a))$. G3 patients showed a significantly higher LV telediastolic volume $(p<0.01)$, LV telediastolic volume index $(p<0.01)$,
LV telesystolic volume $(p<0.01)$, LV telesystolic volume index $(p<0.01)$, LV mass $(p<0.01)$, LV mass index $(p<0.01)$, VD telesystolic volume $(p<0.01)$, and VD telesystolic volume index $(p<0.01)$ when compared to the other groups. There were no differences in the VD telediastolic volumes and VD telediastolic indexes between the groups. This predominant distribution at the inferolateral wall of the LV and a heterogeneous distribution inside the myocardium is in concordance with prior studies $[7,14,24-26]$. 
TABle 2: Clinical characteristics of Chagas heart disease in patients with cardiac edema.

\begin{tabular}{|c|c|c|c|}
\hline & $\begin{array}{l}\text { Edema } \\
(n=8)\end{array}$ & $\begin{array}{l}\text { Nonedema } \\
\quad(n=74)\end{array}$ & $p$ value \\
\hline Age & $53.8($ SD 12.9) & 59.4 (SD 9.5) & 0.12 \\
\hline BMI & $27.9(\mathrm{SD} 4.3)$ & $26.1(\mathrm{SD} 4.3)$ & 0.25 \\
\hline Socioeconomic & 1.75 (SD 0.9) & $2.07(\mathrm{SD} 1.0)$ & 0.39 \\
\hline Female (\%) & $6(75.0)$ & $47(63.5)$ & 0.79 \\
\hline Blood pressure (\%) & $3(37.5)$ & $36(51.4)$ & 0.71 \\
\hline Type 2 diabetes (\%) & $1(12.5)$ & $11(15.7)$ & 0.99 \\
\hline DLP (\%) & $10(16.9)$ & $6(24.0)$ & 0.29 \\
\hline Smoking (\%) & $1(12.5)$ & $2(2.9)$ & 0.71 \\
\hline NYHA & $1.8(\mathrm{SD} 0.5)$ & $1.4(\mathrm{SD} 0.5)$ & 0.12 \\
\hline \multicolumn{4}{|l|}{$C M R$} \\
\hline FEVI & $45.6(\mathrm{SD} 15.4)$ & $54.6(\mathrm{SD} 14.6)$ & 0.10 \\
\hline LGE (\%) & $8(100)$ & $40(54.1)$ & $0.03^{*}$ \\
\hline FEVD & $51.1(\mathrm{SD} 5.9)$ & $54.5(\mathrm{SD} 10.2)$ & 0.36 \\
\hline LV telediastolic volume & $178.0(\mathrm{SD} 78.3)$ & $151.0(\mathrm{SD} 58.3)$ & 0.23 \\
\hline LV telediastolic volume index & $104.0(\mathrm{SD} 51.6)$ & $85.3(\mathrm{SD} \mathrm{32.3)}$ & 0.15 \\
\hline LV telesystolic volume & $118.0(\mathrm{SD} 79.4)$ & $74.2(\mathrm{SD} 56.7)$ & $0.04^{*}$ \\
\hline LV telesystolic volume index & $69.6(\mathrm{SD} 50.1)$ & $41.4(\mathrm{SD} 31.6)$ & $0.03^{*}$ \\
\hline VD telediastolic volume & $142.0(\mathrm{SD} 23.7)$ & $127.0(\mathrm{SD} 43.9)$ & 0.34 \\
\hline VD telediastolic volume index & $81.0($ SD 10.4) & $71.1(\mathrm{SD} 22.0)$ & 0.21 \\
\hline VD telesystolic volume & $66(\mathrm{SD} 17.2)$ & $58.2(\mathrm{SD} 30.2)$ & 0.47 \\
\hline VD telesystolic volume index & $39.0(\mathrm{SD} 7.6)$ & $33.4(\mathrm{SD} 15.6)$ & 0.31 \\
\hline \multicolumn{4}{|l|}{$L G E$} \\
\hline Transmural (\%) & $3(37.5)$ & $12(16.2)$ & 0.32 \\
\hline Midwall (\%) & $7(87.5)$ & $24(32.4)$ & $0.01^{*}$ \\
\hline Subendocardic (\%) & $2(25.0)$ & $15(20.3)$ & 0.99 \\
\hline Subepicardic (\%) & $7(87.5)$ & $12(16.2)$ & $0.00^{*}$ \\
\hline Basal (\%) & $7(87.5)$ & $27(67.5)$ & 0.47 \\
\hline Septal (\%) & $2(25.0)$ & $8(20.0)$ & 0.99 \\
\hline Mesial (\%) & $1(12.5)$ & $16(40.0)$ & 0.28 \\
\hline Apical (\%) & $4(50.0)$ & $17(42.5)$ & 0.99 \\
\hline \multicolumn{4}{|l|}{ Laboratory } \\
\hline Creatinine & $0.9(\mathrm{SD} 0.2)$ & $0.9(\mathrm{SD} 0.2)$ & 0.93 \\
\hline BUN & $20.5(\mathrm{SD} 6.9)$ & $17.2(\mathrm{SD} 8.1)$ & 0.40 \\
\hline
\end{tabular}

Continuous variables are expressed as mean (SD, standard deviation). Categorical variables are expressed as number of patients(\%). ${ }^{*}$ Significant difference between cardiac edema and nonedema patients.

Our confirmation of myocardial fibrosis in Chagas-seropositive patients, in different stages of disease severity, coincides with previous studies that reported myocardial fibrosis in patients within the indeterminate form [22]. Previous studies have quantified myocardial fibrosis by CMR in Chagas disease patients [16, 26, 27]. Rochitte et al. evaluated CMR with the use of LGE and reported fibrosis in $68.6 \%$ of all individuals evaluated and $100 \%$ in those with ventricular tachycardia [15]. Noya-Rabelo et al. detected LGE in $64 \%$ of patients with Chagas disease [27]. In addition, Regueiro et al. reported fibrosis in $7.4 \%$ of patients in the indeterminate form, $15.8 \%$ in the cardiac stage without ventricular dysfunction, and $52.4 \%$ in those with ventricular dysfunction. It is important to stress that myocardial fibrosis detected within the indeterminate form can be present in such low degrees that do not lead to myocardial dysfunction or remodeling, which requires very sensitive techniques to be detected [22]. In this way, CMR was considered in this study because it has been considered a sensitive technique to detect small myocardial tissue abnormalities in Chagas heart disease, hardly detected by traditional methods, such as echocardiogram, and stands out amongst imaging techniques in the quantification of myocardial fibrosis in this disease $[6,14-16,18,22]$.

We found that patients with LGE had a trend toward worse NYHA functional class compared to patients without LGE, although LGE was found in $25(52.1 \%)$ patients with NYHA functional class I and $22(45.8 \%)$ patients with NYHA functional class II, and it was found in a patient with NYHA functional class III. LVEF and CMR-derived LV volumes showed high negative correlation with echocardiographic measurements for LV telediastolic volume $\left(r_{s}=-0.75\right), \mathrm{LV}$ telediastolic volume index $\left(r_{s}=-0.77\right), \mathrm{LV}$ telesystolic volume $\left(r_{s}=-0.90\right), \mathrm{LV}$ telesystolic volume index $\left(r_{s}=-0.91\right)$, LV mass $\left(r_{s}=-0.71\right)$, and LV mass index $\left(r_{s}=-0.73\right)$. In addition, LVEF showed a high positive correlation with RVEF $\left(r_{s}=-0.69\right)$ as shown in Figure 2(b).

Although usually associated with reduced LVEF, we found that RVEF was significantly lower in G3 patients. This finding is in accordance with recent studies which suggest that RV systolic dysfunction in Chagas disease depends mainly on LV increased afterload [28, 29]. 


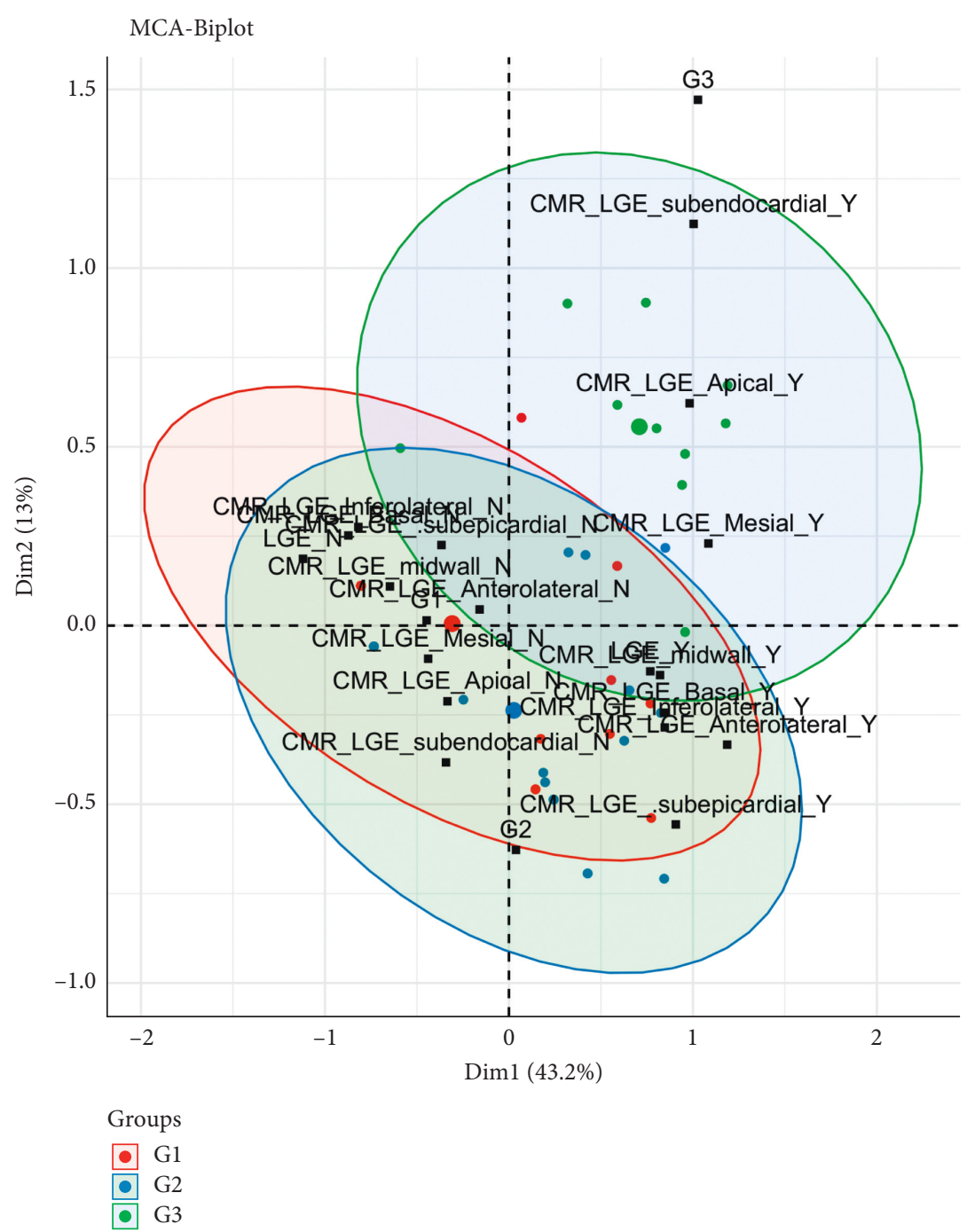

FIGURE 3: Multiple correspondence analyses of the variables associated with the presence and location of LGE within LVEF groups. It shows the difference between the variables associated with G3 versus G2 and G1 groups.

Furthermore, the VD telesystolic volume and VD telesystolic volume index were statistically higher in G3 patients $(p<0.05)$. Prominent inflammation, fibrosis, and vasculitis in the right chambers were shown in experimental models of mice infected with T. cruzi, even during the acute infection phase [30]. In humans, endomyocardial biopsies on the right side of the interventricular septum revealed histopathologic abnormalities in most patients with chronic Chagas disease $[31,32]$.

Edema was observed in $8(9.8 \%)$ patients, $2(5.4 \%)$ of $\mathrm{G} 1$, 4 (12.1\%) of G2, and 2 (16.7\%) of G3. It was observed mainly at the basal inferolateral segment in 7 (87.5\%) cases. Edema distribution is represented in a 17-segment model in Figure 1(b). All patients with cardiac edema presented LGE, being that it was located more frequently in the subepicardium and mesocardium when compared with nonedema patients $(p<0.05)$. Greater LV telesystolic volume and LV telesystolic volume index were found in those patients $(p<0.05)$. Table 2 shows the clinical characteristics of patients with cardiac edema.
The presence of edema in the chronic phase of the disease was previously related with severe impairment of myocardial status [22] and may represent the evidence that the inflammation of Chagas disease is maintained for an extended period after the acute phase, as previously reported. Thus, edema finding is probably related to the persistence of an active inflammatory process in the chronic phase.

In Figure 3, it is possible to visualize a structural organization for the variables and categories in a dimensional space, which allows the identification of patterns in the data and associations between the investigated parameters. Although we observed a heterogeneous LGE pattern, as previously reported [26, 27], an association between belonging to G3 and the presence of LGE in the subendocardial segment in apical and mesial locations were found in the MCA analysis, whose first two dimensions accounted for almost $60 \%$ of the variability between groups. An association between belonging to G3 and the presence of LGE in the subendocardial segment in apical and mesial locations is easy to perceive in Figure 3. Although it seems that 
belonging to G2 and presence of LGE in the midwall and subepicardial segments in a basal, inferolateral, and anterolateral locations are associated, this relation is not supported by the analysis. On the contrary, despite being in different quadrants, there is no clear division between the variables associated with G1 and G2 patients.

Our findings indicate that the concept of indeterminate form of Chagas disease, although valid for the collective prognostic evaluation of this group of patients, should be updated in the analysis of individual cases, considering the findings obtained by the application of more accurate diagnostic methods, such as CMR [14, 15, 18, 33-35]. So, even chagasic patients with little or no clinical manifestation of cardiac involvement and performing risk activities or requiring effort should be considered for further careful analysis in order to identify subclinical myocardial damage and risk assessment and prevention of cardiac dysfunction.

\section{Conclusions}

The aim of this study was to characterize CMR findings caused by Chagas at different stages of disease severity in Chagas-seropositive patients and solve the hypothesis that edema could occur in patients with chronic chagasic cardiomyopathy and corresponds to the persistence of the inflammatory process in the myocardium. We found that edema can be found in patients with chagasic cardiomyopathy in the chronic stage. In later stages of cardiac dilation with low LVEF, the LGE pattern involves subendocardium and mid locations. Deteriorations of RV and LV are positively correlated without evidence of fibrosis in the RV.

\section{Data Availability}

The data used to support the findings of this study may be released upon application to the Fundación Universitaria de Ciencias de la Salud (FUCS), Bogotá, Colombia, who can be contacted at gestion.conocimiento@fucsalud.edu.co.

\section{Conflicts of Interest}

The authors declare that there are no conflicts of interest regarding the publication of this paper.

\section{Acknowledgments}

Special thanks go to Tania Sánchez Vargas and the fellows: Dr. Lorena Gonzalez Russi, Dr. Juan Sebastián Salcedo, Dr. Camilo Calvache, and Dr. Leonor Mariño. The authors thank the financial support of the Departamento Administrativo de Ciencia, Tecnología e Innovación-COLCIENCIAS, Colombia (Convocatoria 744/2016).

\section{References}

[1] M. C. P. Nunes, W. Dones, C. A. Morillo, J. J. Encina, and A. L. Ribeiro, "Chagas disease," Journal of the American College of Cardiology, vol. 62, no. 9, pp. 767-776, 2013.
[2] World Health Organization, "Chagas disease: control and elimination," Sixty-third World Health Assembly, vol. 1, pp. 1-4, 2010.

[3] ACC Task Force Members, "ACCF/ACR/AHA/NASCI/ SCMR2010. Expert consensus document on cardiovascular magnetic resonance a report of the American college of cardiology foundation task force on expert consensus documents," Circulation, vol. 121, no. 22, pp. 2462-2508, 2010.

[4] K. Stergiopoulos, E. Shiang, and T. Bench, "Pregnancy in patients with pre-existing cardiomyopathies," Journal of the American College of Cardiology, vol. 58, no. 4, pp. 337-350, 2011.

[5] Instituto Nacional de Salud, 2017 , http://www.ins.gov.co/ temas-de-interes/Paginas/hagas.aspx.

[6] E. B. Falchetto, C. Simone, S. Costa, and C. E. Rochitte, "Diagnostic challenges of chagas cardiomyopathy and CMR imaging," Global Heart, vol. 10, no. 3, pp. 181-187, 2015.

[7] M. A. Rossi, "The pattern of myocardial fibrosis in chronic chagas' heart disease," International Journal of Cardiology, vol. 30, no. 3, pp. 335-340, 1991.

[8] C. Mady, R. H. Cardoso, A. C. Barretto, P. L. da Luz, G. Bellotti, and F. Pileggi, "Survival and predictors of survival in patients with congestive heart failure due to chagas' cardiomyopathy," Circulation, vol. 90, no. 6, pp. 3098-3102, 1994.

[9] H. F. G. Freitas, P. R. Chizzola, Â. T. Paes, A. C. P. Lima, and A. J. Mansur, "Risk stratification in a Brazilian hospital-based cohort of 1220 outpatients with heart failure: role of chagas' heart disease," International Journal of Cardiology, vol. 102, no. 2, pp. 239-247, 2005.

[10] A. P. Barbosa, A. Cardinalli Neto, A. P. Otaviano, B. F. Rocha, and R. B. Bestetti, "Comparação do desfecho entre a cardiopatia chagásica e a miocardiopatia dilatada idiopática," Arquivos Brasileiros de Cardiologia, vol. 97, no. 6, pp. 517-525, 2011.

[11] R. B. Bestetti, O. C. Freitas, G. Muccillo, and J. S. M. Oliveira, "Clinical and morphological characteristics associated with sudden cardiac death in patients with chagas' disease," European Heart Journal, vol. 14, no. 12, pp. 1610-1614, 1993.

[12] N. Mewton, C. Y. Liu, P. Croisille, D. Bluemke, and J. A. C. Lima, "Assessment of myocardial fibrosis with cardiovascular magnetic resonance," Journal of the American College of Cardiology, vol. 57, no. 8, pp. 891-903, 2011.

[13] J. A. White and M. R. Patel, "The role of cardiovascular MRI in heart failure and the cardiomyopathies," Cardiology Clinics, vol. 25 , no. 1, pp. 71-95, 2007.

[14] G. J. Volpe, H. T. Moreira, H. S Trad et al., "Left ventricular scar and prognosis in chronic chagas cardiomyopathy," Journal of the American College of Cardiology, vol. 72, no. 21, pp. 2567-2576, 2018.

[15] C. E. Rochitte, P. F. Oliveira, J. M. Andrade et al., "Myocardial delayed enhancement by magnetic resonance imaging in patients with chagas' disease," Journal of the American College of Cardiology, vol. 46, no. 8, pp. 1553-1558, 2005.

[16] C. E. Rochitte, M. S. Nacif, A. C. de Oliveira Júnior et al., "Cardiac magnetic resonance in chagas' disease," Artificial Organs, vol. 31, no. 4, pp. 259-267, 2007.

[17] L. M. M. Uellendahl, "Detection of myocardial fibrosis by cardiovascular magnetic resonance imaging in patients with chagas disease: correlation with clinical presentation and risk stratification," PhD. thesis, São Paulo: University of São Paulo Medical School, São Paulo, Brazil, 2007, http://www.teses.usp.br/teses/.

[18] T. Senra, B. M. Ianni, A. C. P. Costa et al., "Long-term prognostic value of myocardial fibrosis in patients with chagas cardiomyopathy," Journal of the American College of Cardiology, vol. 72, no. 21, pp. 2577-2587, 2018. 
[19] K. C. Wu, R. G. Weiss, D. R. Thiemann et al., "Late gadolinium enhancement by cardiovascular magnetic resonance heralds an adverse prognosis in nonischemic cardiomyopathy," Journal of the American College of Cardiology, vol. 51, no. 25, pp. 2414-2421, 2008.

[20] H. Abdel-Aty, P. Boyé, A. Zagrosek et al., "Diagnostic performance of cardiovascular magnetic resonance in patients with suspected acute myocarditis," Journal of the American College of Cardiology, vol. 45, no. 11, pp. 1815-1822, 2005.

[21] J.-P. Laissy, B. Messin, O. Varenne et al., "MRI of acute myocarditis," Chest, vol. 122, no. 5, pp. 1638-1648, 2002.

[22] J. Steg, B. M. Ianni, C. Mady et al., "Myocardial tissue characterization in chagas' heart disease by cardiovascular magnetic resonance," Journal of Cardiovascular Magnetic Resonance, vol. 17, no. 1, p. 97, 2015.

[23] R Core Team, R: A Language and Environment for Statistical Computing, R Foundation for Statistical Computing, Vienna, Austria, 2017, https://www.R-project.org/.

[24] S. A. P. Palomino, V. D. Aiello, and M. L. Higuchi, "Systematic mapping of hearts from chronic chagasic patients: the association between the occurrence of histopathological lesions and Trypanosoma cruzi antigens," Annals of Tropical Medicine \& Parasitology, vol. 94, no. 6, pp. 571-579, 2000.

[25] J. Guarner, J. Bartlett, S. R. Zaki, M. J. Grijalva, D. G. Colley, and M. R. Powell, "Mouse model for chagas disease: immunohistochemical distribution of different stages of Trypanosoma cruzi in tissues throughout infection," The American Journal of Tropical Medicine and Hygiene, vol. 65, no. 2, pp. 152-158, 2001.

[26] A. Regueiro, A. García-Álvarez, and M. Sitges, "Myocardial involvement in chagas disease: insights from cardiac magnetic resonance," International Journal of Cardiology, vol. 165, no. 1, pp. 107-112, 2013.

[27] M. M. Noya-Rabelo, T. Larocca, A. Machado et al., "The presence and extension of myocardial fibrosis in the undetermined form of chagas' disease: a study using magnetic resonance," Arquivos brasileiros de cardiologia, vol. 110, no. 2, pp. 124-131, 2018.

[28] M. D. C. P. Nunes, M. d. M. Barbosa, V. A. A. Brum, and M. O. D. C. Rocha, "Morphofunctional characteristics of the right ventricle in chagas' dilated cardiomyopathy," International Journal of Cardiology, vol. 94, no. 1, pp. 79-85, 2004.

[29] M. M. Barbosa, M. O. C. Rocha, and D. F. Vidigal, "Early detection of left ventricular contractility abnormalities by two-dimensional speckle tracking strain in chagas' disease," Echocardiography, vol. 31, no. 5, pp. 623-630, 2014.

[30] L. A. Jelicks, S. M. Factor, V. L. Braunstein et al., "Application of cardiac gated magnetic resonance imaging in murine chagas' disease," The American Journal of Tropical Medicine and Hygiene, vol. 61, no. 2, pp. 207-214, 1999.

[31] C. Mady, A. C. Barretto, N. Stolf et al., "Endomyocardial biopsy in the indeterminate form of chagas' disease," Arquivos Brasileiros de Cardiologia, vol. 36, no. 6, pp. 387-390, 1981.

[32] H. A. Carrasco Guerra, E. Palacios-Prü, C. Dagert de Scorza, C. Molina, G. Inglessis, and R. V. Mendoza, "Clinical, histochemical, and ultrastructural correlation in septal endomyocardial biopsies from chronic chagasic patients: detection of early myocardial damage," American Heart Journal, vol. 113 , no. 3, pp. 716-724, 1987.

[33] A. Pazin-Filho, M. M. D. Romano, O. C. Almeida-Filho et al., "Minor segmental wall motion abnormalities detected in patients with chagas' disease have adverse prognostic implications," Brazilian Journal of Medical and Biological Research, vol. 39, no. 4, pp. 483-487, 2006.
[34] D. G. Strauss, S. Cardoso, J. A. C. Lima, C. E. Rochitte, and K. C. Wu, "ECG scar quantification correlates with cardiac magnetic resonance scar size and prognostic factors in chagas' disease," Heart, vol. 97, no. 5, pp. 357-361, 2011.

[35] J. González, J. P. Fragola, F. Azzato, and J. Milei, "La muerte súbita no es frecuente en la enfermedad de chagas crónica sin cardiopatía demostrable," Revista Argentina de Cardiología, vol. 87, no. 1, pp. 52-54, 2019. 


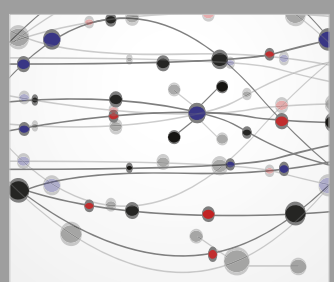

The Scientific World Journal
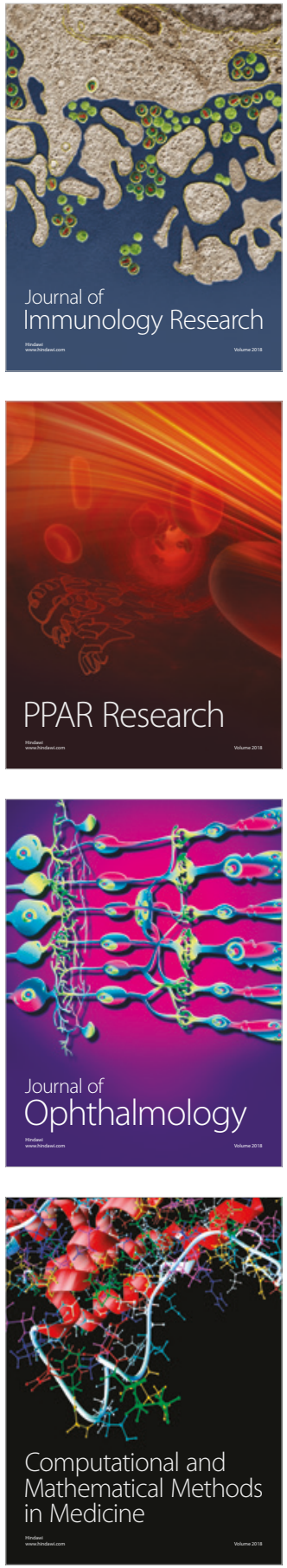

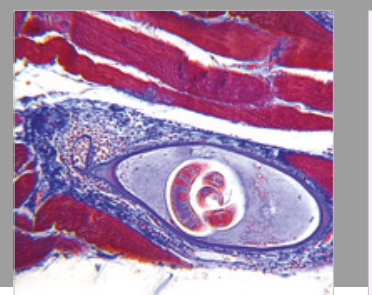

Gastroenterology Research and Practice

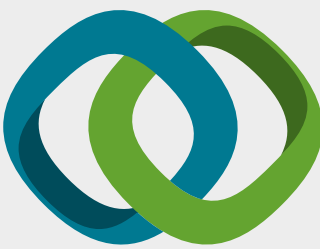

\section{Hindawi}

Submit your manuscripts at

www.hindawi.com
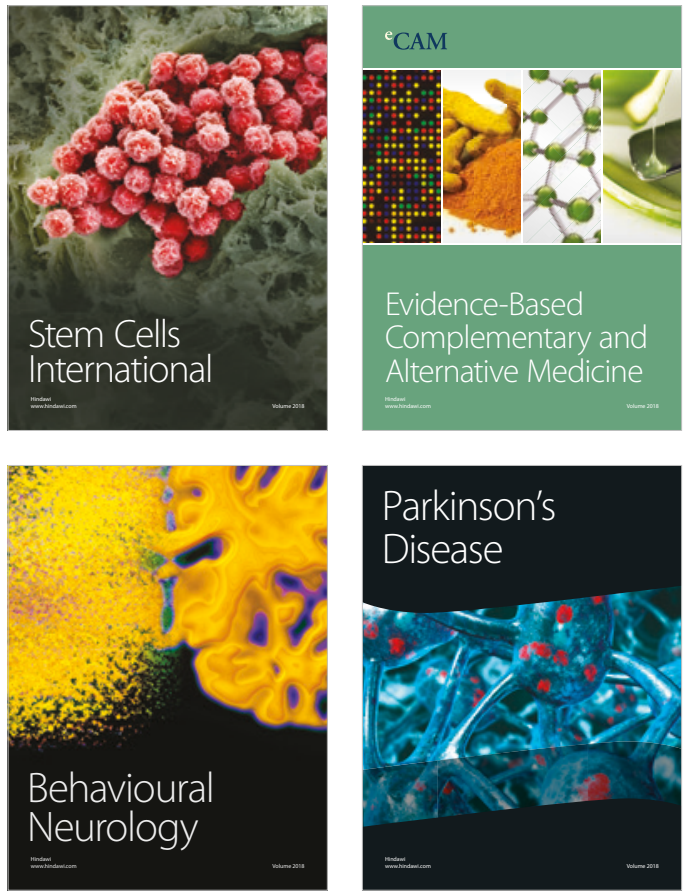

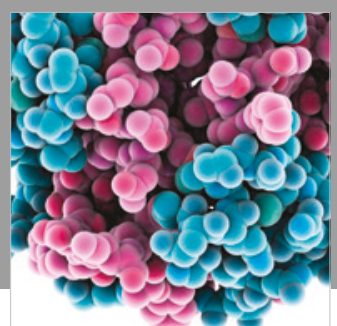

ournal of

Diabetes Research

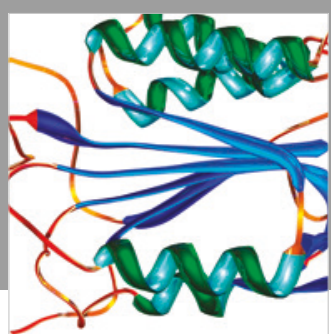

Disease Markers
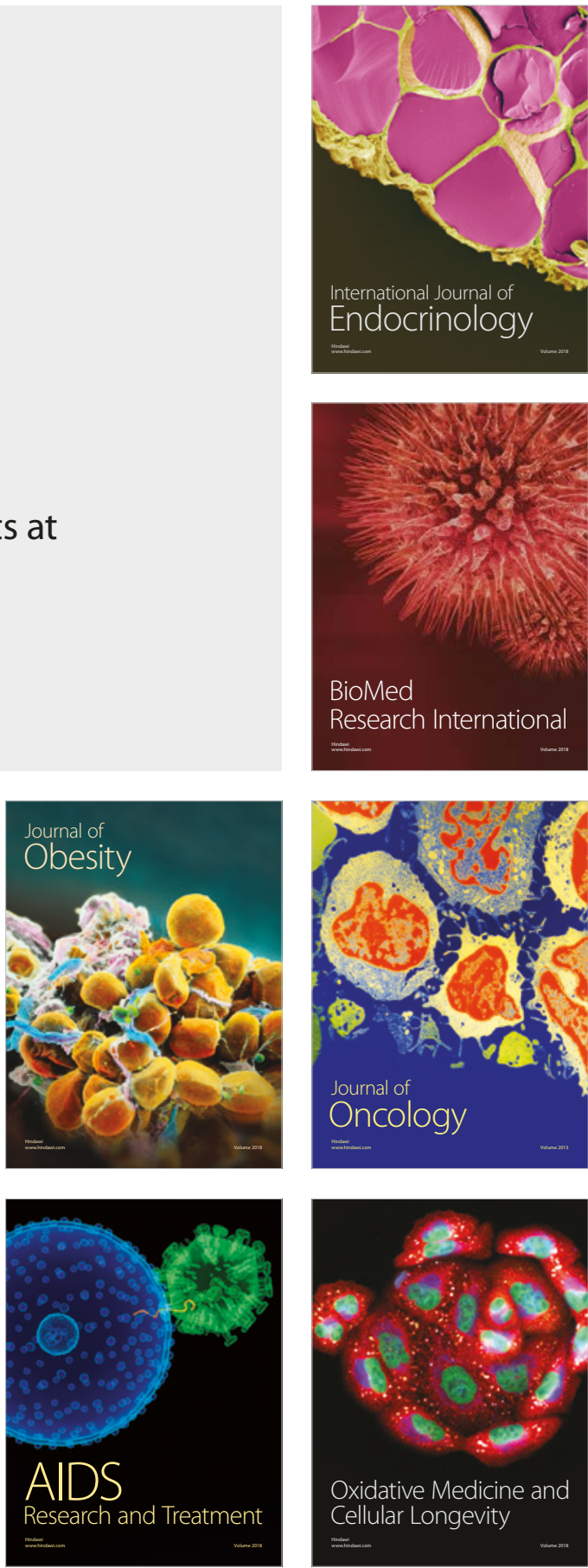